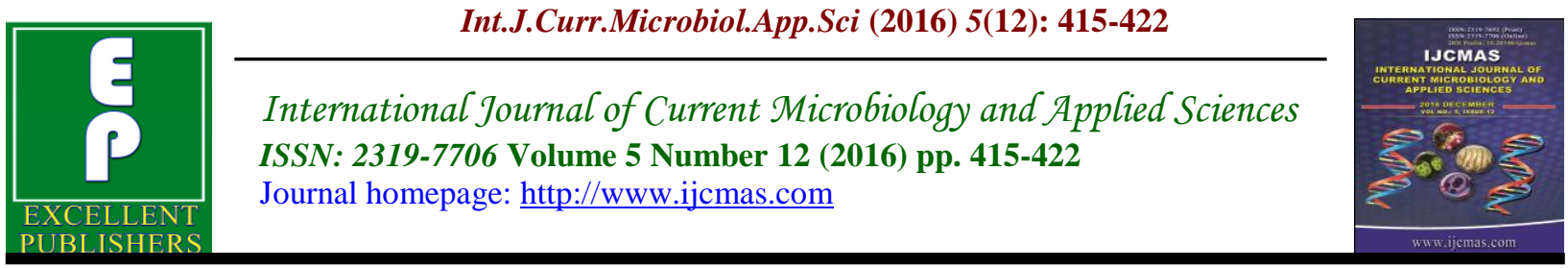

Original Research Article

http://dx.doi.org/10.20546/ijcmas.2016.512.045

\title{
Resistin (RETN) Gene rs1862513 Polymorphisms and Acne vulgaris Patients
}

\author{
Hammadi A. Al-Hilali and Mohammed Jaafar AL-Anssari* \\ Department of Medical Microbiology, Faculty of Medicine, \\ Al-Qadisiya University, Diwaniya, Iraq \\ *Corresponding author
}

\section{Keywords}

Acne vulgaris, RETN, Resistin, Allele, Genotype, RFLP-PCR.

\begin{tabular}{l}
\hline Article Info \\
\hline Accepted: \\
18 November 2016 \\
Available Online: \\
10 December 2016
\end{tabular}

\section{A B S T R A C T}

Acne vulgaris is a multifactorial inflammatory skin disease and the inflammation play an important role in its pathogenesis, many pro-inflammatory adipokines and cytokines contribute to this pathogenesis, from these IL- 8 and resist in which act as pro-inflammatory mediators and encoded by different genes. The present study was conducted to investigate whether RETN-420 C>G gene polymorphism as a predisposing factor to acne vulgaris. 49 Iraqi patients who were suffered from acne vulgaris have enrolled and compared with 25 healthy controls. RFLP-PCR technique was performed to detect the RETN-420 gene polymorphisms. The frequency ofthe genotypes in acne patients were $(\mathrm{CC}=6 \%, \mathrm{CG}=14 \%$ and $\mathrm{GG}=80 \%)$, while in control group they were $(8 \%, 24 \%$ and $68 \%)$ respectively. The frequency of all genotypes was not found any significant differences between acne patients and the healthy controls $(\mathrm{P}=0.53)$. No significant difference in genotype frequency regarding the gender between patients and the healthy group can be noted also between the same gender of patients and healthy group, as well as there was no association detected between this type of polymorphism and the degree of severity of acne ( $\mathrm{P}$ value $=0.74$ ). We conclude that $\mathrm{RETN}-420 \mathrm{G}>\mathrm{C}$ single nucleotide polymorphism do not contributewith the pathogenesis of acne vulgaris and there was no significant association between different alleles and the severity of the disease in two gender.

\section{Introduction}

Acne vulgaris is one of the most common chronic skin diseases affecting adolescents, $90 \%$ of an adolescent being affected by some degree (Al-Salih, 2008), however, acne can remain throughout adulthood in 8 $\%$ of the patients (Grange et al., 2010). Clinically, adolescent acne consists of a combination of non-inflammatory (open and closed comedons) and inflammatory (papules, pustules, and nodules) lesions (Webster, 2005). Although acne is not a life-threatening disease, but still can lead to serious physical (permanent scarring and hyper pigmentation) and psychosocial difficulties (depression, anxiety, anger, impairment in self-image) (Fried, 2006). The pathogenesis of acne is currently attributed to multiple factors such as increased sebum production and alteration in its quality, increased androgen activity, follicular hyperkeratinization, proliferation of Propionibacterium acnes (P. acnes) and 
exhibition of pro- and anti-inflammatory properties (Kurokawa et al., 2009). The affected persons' genetic background may also play an important role in acne predisposition, some studies showed that $81 \%$ of the variance of the disease was attributable to additive genetic effects and the remaining $19 \%$ was attributable to environmental factors(emotional stress, drugs, food, menstruation, smoking) (He et al., 2006).

Resistin, also called adipocyte-secreted factor (ADSF), found in inflammatory zone 3 (FIZZ3), is a novel hormone secreted by adipocytes (Holcomb et al., 2000). Resistin belongs to a family of cysteine-rich $\mathrm{C}$ terminal proteins, termed RELMs (ResistinLike Molecule) (Gerstmayer et al., 2003). It was found that human resistin is mainly synthesized by non-adipocytes inflammatory resident cells such as peripheral blood mononuclear cells (PBMCs), bone marrow cells, monocytes and most predominantly by macrophages (Nagaev et al., 2006; Kunnari et al., 2009).

The resistin acts as an inflammatogenic cytokine have potent proinflammatory properties as it triggers the release of TNF$\alpha$, IL-1, and IL-6 (Bokarewa et al., 2005). In effect, mounting evidence has identified neutrophils as dominant sources of resistin at the site of inflammation and even systemically during severe bacterial infections (Bostrom et al., 2009; Johansson et al., 2009). It promote inflammation (Lehrke et al., 2004; Bokarewa et al., 2005). The human resistin gene (RETN) is sited on chromosome 19p13 (Menzaghi et al., 2006). Several single nucleotide polymorphisms (SNPs) have been associated with resistin levels (Osawa et al., 2007; Azuma et al., 2004; Cho et al., 2004). The levels of resistin and their gene polymorphism may contribute to many inflammatory diseases such as inflammatory bowel disease (Konrad et al., 2007), chronic pancreatitis (Adrych et al., 2009), and in other disease.

\section{Materials and Methods}

\section{Patients}

The subjects enrolled in this study was comprised of 49 patients ( 28 female and 21 male) who were suffering from acne vulgaris and there ages are between 13 and 35 years, and the healthy control individuals of 25 (16 female and 9 male) with ages ranges of 14-40 years old, thy were attended at Dermatology Center of Al-Sader medical City and Dr. Mohsen Dalimy Clinic, the acne vulgaris was diagnosed by consultant physicians based on physical examination, and Global Acne Grading System (Jerry KL Tan, 2008).Patients were divided into three sub-categories, as: acne comedonica (mild acne), acne papulo-pustulosa (moderate acne), and nodulo-cystic acne (severe acne). Healthy controls with no symptoms of Acne vulgaris or other skin diseases were enrolled in this study from the same ethnic region as patients.

\section{Methods}

The DNA was extracted from whole blood, after collected, by special kit and the RETN gene was amplified by PCR technique by the use of specific primers for this gene (forward $\mathrm{F}$ primer 5'-TGT CAT TCT CAC CCA GAG ACA-3' and reverse R primer 5'-TGG GCT CAG CTA ACC AAA TC$\left.3^{\prime}\right)$. PCR was carried out with the following thermal cycling conditions: an initial preparation step at $94{ }^{\circ} \mathrm{C}$ for $5 \mathrm{~min}$., followed by amplification for 40 cycles at $94{ }^{\circ} \mathrm{C}$ for $1 \mathrm{~min} ., 57^{\circ} \mathrm{C}$ for $1.5 \mathrm{~min}$., and 72 ${ }^{\circ} \mathrm{C}$ for $1.5 \mathrm{~min}$., followed by the end cycle at $72{ }^{\circ} \mathrm{C}$ for $7 \mathrm{~min}$. Then the PCR product was incubated over night with BpiI restriction 
enzyme to cut the gene to show the polymorphisms under UV light by using gel electrophoresis. This Technique was carried out to detect the resistin gene polymorphism SNP -420 $(\mathrm{G}>\mathrm{C})$ in RETN gene in the samples of both patients with acne vulgaris and as well as the control group.

\section{Statistical analysis}

Statistical analysis was done by using SPSS (statistical package for social sciences) version 20 in which we use ANOVA(analysis of variance), independent sample T-test, chi square test, and Pearson correlation coefficient as needed. We set $\mathrm{P}$ value $<0.05$ as significant.

\section{Results and Discussion}

\section{RFLP-PCR product appearance}

The product of RFLP-PCR technique showed the single nucleotide polymorphism (SNP) that occur in RETN-420 (rs1862513) and show three bands in size 533bp, 323bp and 210bp this means there is three genotype polymorphism; CC homozygous when two band 323bp and 210bp will appear, GG homozygous when one band 533bp will appear and CG heterozygous when the three band will appear as shown in figure(1), and this result was agreed with the earlier report of Kumar et al., (2014), that this locus had three genotypes only.

\section{Genotype distributions in subjects under study}

In the current study, a direct comparison between resistin genotypes and the clinical features of acne vulgaris (susceptibility \& severity) was investigated focusing on the two alleles single nucleotide polymorphism in RETN gene in the context of the promoter region. The frequency of genotypes in acne patients were as follow: $\mathrm{CC}(3 \%), \mathrm{CG}(7 \%)$ \& GG(39\%) ; while in the healthy control subjects: $\mathrm{CC}(2 \%), \quad \mathrm{CG}(6 \%) \& \mathrm{GG}(17 \%)$, figure(2). The genotype distribution had no deviation from Hardy-Weinberg equilibrium (HWE) in all groups.

The GG genotype frequency was higher in acne patients $(80 \%)$ when compare with healthy controls $(68 \%)$, but the difference in the distribution of RETN genotypes between patient and control groups was statistically non-significant, $(\mathrm{Chi}=1.27 \& \mathrm{P}$-value $=0.53)$, as shown in the table (1). This result was contrast with the results of Hussain et al., (2015 B) on acne vulgaris in Pakistani population $(\mathrm{Chi}=8.5 \& \mathrm{p}$-value $=0.014)$, this support the null hypothesis that there is no association between the RETN-240 C>G SNP polymorphism and the susceptibility to the disease, these differences may be explained by the difference in the geographically different population studied

The distribution of the Genotypes in acne and healthy control subjects according to gender

The results of this study according to the three genotype distributions in acne patients show that there is no gender-specific differences were detected between male and females in acne patients, the $P$ value $=0.15$ for all genotypes as shown in table (2), according to our knowledge there is no study demonstrate this association.

When Compare between the study groups regarding the same gender, the data showed that there was no association between the RETN-420 >C polymorphism and the two genders of acne patients $(\mathrm{P}$ value $=0.15)$ as shown in figure (3) for female and (4)for male, These results was not completely accordant with the results of Younis et al., 
(2016), that show that the variant genotype is associated with acne in female patients ( $p$ $=0.008$ ) whereas, in male patients the variant genotype frequency, while higher, did not reach statistical significance.

The association between RETN-420 C>G polymorphism and the severity of acne

In this study there is no association was detected between the severity of acne and the distribution of the frequency of the three genotypes in acne patients, in which the $P$ value $=0.74$ ) as shown in the table (3). This result contrast with Younis et al., (2016), show that both $\mathrm{G} / \mathrm{G}$ genotype and $\mathrm{G}$ allele frequencies in $-420 \mathrm{C}>\mathrm{G}$ polymorphism are associated with severity of acne symptoms (G/G: $p=0.027 ; G: p=0.020)$.In view of acne is a multifactorial disease, it is possible that the severity of acne may be readily influenced by other factors such as environmental and other genetic elements (Cordian et al., 2002; Szabo \& Kemeny, 2011).

Table.1 Genotype distribution of resistin RETN-420 gene polymorphism in patients and controls

\begin{tabular}{|cccccc|}
\hline Genotypes & $\begin{array}{c}\text { Controls } \\
\mathrm{N}(\%)\end{array}$ & $\begin{array}{c}\text { Patients } \\
\mathrm{N}(\%)\end{array}$ & OR & $\mathrm{P}$ & Chi \\
\hline CC & $2(8 \%)$ & $3(6 \%)$ & 0.75 & & \\
CG & $6(24 \%)$ & $7(14 \%)$ & 0.59 & & \\
GG & $17(68 \%)$ & $39(80 \%)$ & 1.83 & & \\
Total & $25(100 \%)$ & $49(100 \%)$ & & & \\
\hline
\end{tabular}

Table.2 Genotypes distribution of RETN-420 gene polymorphism among acne patients according to the gender

\begin{tabular}{|cccccc|}
\hline Genotypes & $\begin{array}{c}\text { Female } \\
\mathbf{N}(\%)\end{array}$ & $\begin{array}{c}\text { Male } \\
\text { N(\%) }\end{array}$ & OR & Chi & P value \\
\hline CC & $1(3.6 \%)$ & $2(9.5 \%)$ & 2.83 & & \\
CG & $2(7.1 \%)$ & $5(23.8 \%)$ & 4.06 & & \\
GG & $25(89.2 \%)$ & $14(66.7 \%)$ & 0.24 & & \\
Total & $28(100 \%)$ & $21(100 \%)$ & & \\
\hline
\end{tabular}


Table.3 The association between RETN-420 C>G polymorphism and degree of severity of acne patients

\begin{tabular}{|ccccc|}
\hline Genotype & $\begin{array}{c}\text { Mild } \\
\text { N }(\%)\end{array}$ & $\begin{array}{c}\text { Moderate } \\
\text { N }(\%)\end{array}$ & $\begin{array}{c}\text { Severe } \\
\text { N }(\%)\end{array}$ & P-value \\
\hline CC & $1(5.3 \%)$ & $2(7.15 \%)$ & $0(0 \%)$ & \\
CG & $4(21 \%)$ & $3(10.7 \%)$ & $0(0 \%)$ & 0.74 \\
$*$ GG & $14(73.6 \%)$ & $23(82.15 \%)$ & $2(100 \%)$ & \\
Total & $19(100 \%)$ & $28(100 \%)$ & $2(100 \%)$ & \\
\hline
\end{tabular}

Fig.2 Case-control comparison in the relative frequency of the three selected genotypes (CC, CG and GG).

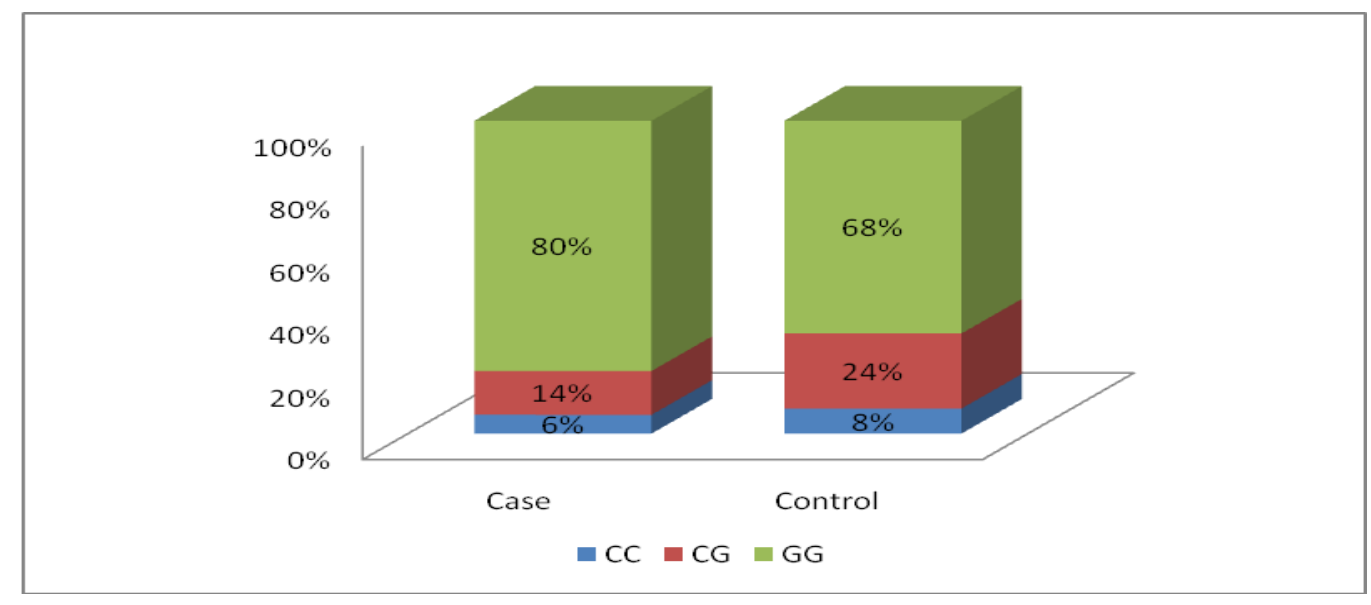

Fig.3 Case -control comparison in the relative frequency of the three selected genotypes in females

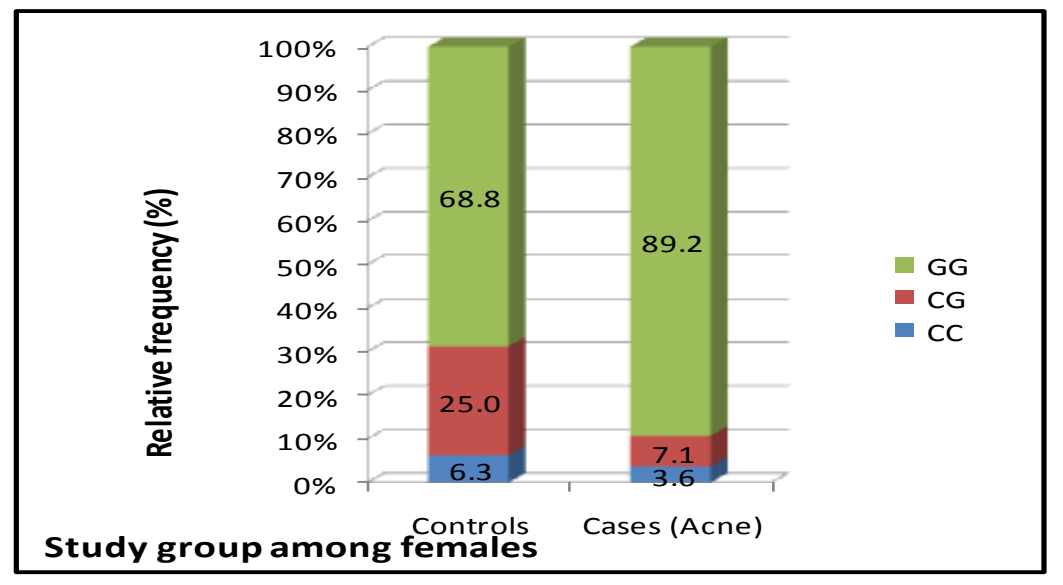


Fig.4 Case -control comparison in the relative frequency of three selected genotypes in males

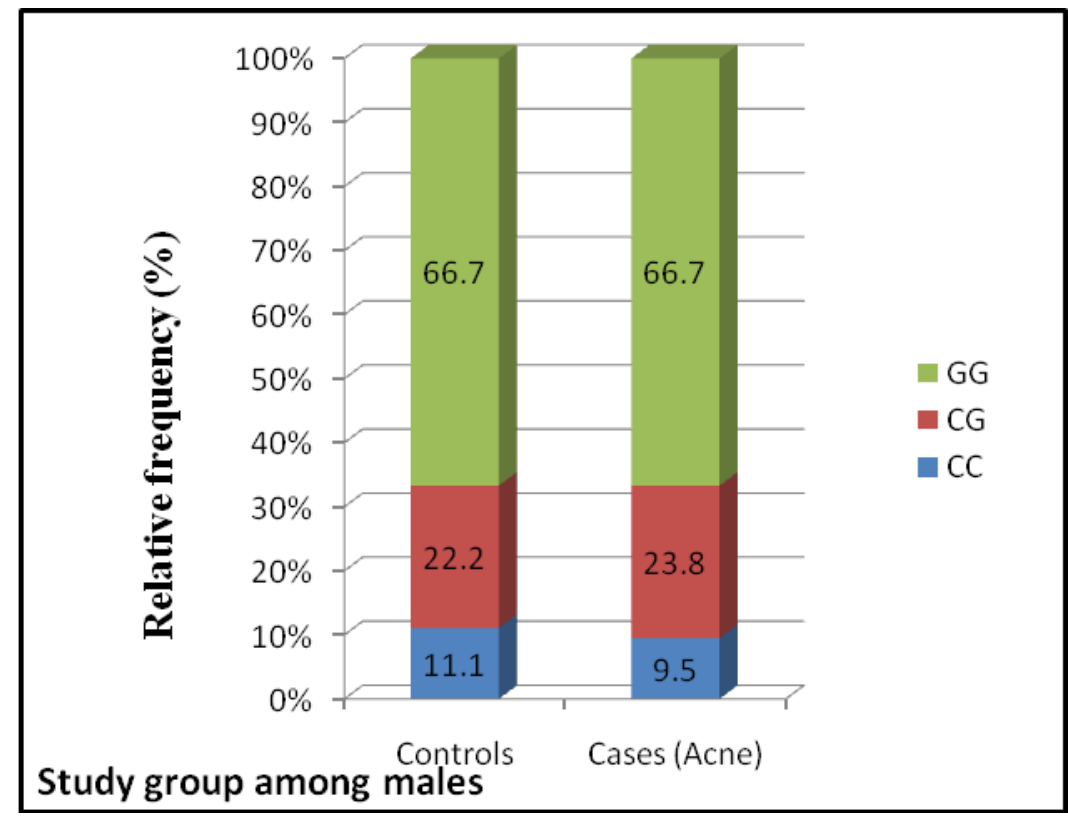

The association between RETN-420 C>G polymorphism and the severity of acne

In this study there is no association was detected between the severity of acne and the distribution of the frequency of the three genotypes in acne patients, in which the $P$ value $=0.74)$ as shown in the table (3).

This result contrast with Younis et al., (2016), show that both G/G genotype and G allele frequencies in $-420 \mathrm{C}>\mathrm{G}$ polymorphism are associated with severity of acne symptoms (G/G: $p=0.027$; $\mathrm{G}: \mathrm{p}=$ 0.020 ).In view of acne is a multifactorial disease, it is possible that the severity of acne may be readily influenced by other factors such as environmental and other genetic elements (Cordian et al., 2002; Szabo \& Kemeny, 2011).

In conclusion, there is no prospect association between RETN-420(C $>$ G) single nucleotide polymorphism and the presence or development of acne vulgaris in two genders and there is no association between the presence of different genotypes or alleles in the population may predict the probability of developing the disease.

\section{References}

Adrych et al. 2009. Increased Serum Resistin Concentration in Patients With Chronic Pancreatitis, J. Clin. Gastroenterol., 43-1: 63-68.

Al-Salih, M.M. 2008. Theraputic evaluation of $2 \%$ Tea Lotion in comparison with $5 \%$ zinc sulphate solution in the treatment of acne vulgaris and rosacea. A thesis submitted to the Iraqi board for medical specialization; dermatology and venerology.

Al-Shobaili, H.A., Salem, T.A., Alzolibani, A.A., Robaee, A.A., Settin, A.A., et al. 2012. Tumor necrosis factor- $\alpha-308$ G/A and interleukin $10-1082$ A/G gene polymorphisms in patients with Acne vulgaris. J. Dermatol. Sci., 68: 52-55.

Azuma, K., Oguchi, S., Matsubara, Y., Mamizuka, T., Murata, M., Kikuchi, H., Watanabe, K., Katsukawa, F., Yamazaki, H., Shimada, A., Saruta, T. 
2004. Novel resistin promoter polymorphisms: association with serum resistin level in Japanese obese individuals. Horm. Metab. Res., 36: 564-570.

Bokarewa, M., Nagaev, I., Dahlberg, L., Smith, U., Tarkowski, A. 2005. Resistin, an adipokine with potent proinflammatory properties. $J$. Immunol., 174(9): 5789-5795.

Bokarewa, M., Nagaev, I., Dahlberg, L., Smith, U., Tarkowski, A. 2005. Resistin, an adipokine with potent proinflammatory properties. $J$. Immunol., 174(9): 5789-5795.

Bostrom, E.A., Tarkowski, A., Bokarewa, M. 2009. Resistin is stored in neutrophil granules being released upon challenge with inflammatory stimuli. Biochim. Biophys. Acta, 1793: 1894-1900.

Cho, Y.M., Youn, B.S., Chung, S.S., Kim, K.W., Lee, H.K., Yu, K.Y., Park, H.J., Shin, H.D., Park, K.S. 2004. Common genetic polymorphisms in the promoter of resistin gene are major determinants of plasma resistin concentrations in humans. Diabetologia, 47(3):559-565.

Cordian, L., Linerberg, S., Hurtado, M., Hill, K., Eaton, S. and Brand, J. 2002. Acne vulgaris: a disease of western civilization. Arch. dermatol., 138: 1584-1590.

Doshi, A., Zaheer, A., Stiller, M.J.A. 1997. comparison of current acne grading systems and proposal of a novel system. Int. J. Dermatol., 136: 416418.

Fried, R.G. 2006. Psychological problems in acne patients. Dermatolther., 19: 237 240.

Gerstmayer, B., Kusters, D., Gebel, S., Müller, T., Van Miert, E., Hofmann, K., et al. 2003. Identification of RELM-@, a novel resistin-like molecule with a distinct expression pattern. Genomics, 81: 588-95.

Grange, P., Weil, B., Dubin, N. and Batteux, F. 2010. Does inflammatory acne result from imbulence in the keratinocyte innate immune response? Microbes and infection, 12: 10851090.

He, L., Yang, Z., Yu, H., Cheng, B., et al. 2006. The relationship between CYP17-34T/C polymorphism \& acne in chinese subjects revealed by sequencing. Dermatol., 212: 338-342.

Holcomb, I.N., Kabakoff, R.C., Chan, B., Baker, T.W., Gurney, A., Henzel, W., et al. 2000. FIZZ, a novel cysteinerich secreted protein associated with pulmonary Inflammation, defines a new gene family. EMBO J., 19: 404655.

Hussain, S., Iqba, T., Sadiq, I., Feroz, S., and Satti, H.S. 2015 B. Polymorphism in the IL- 8 Gene Promoter and the Risk of Acne Vulgaris in a Pakistani Population., Iran. J. Allergy Asthma Immunol., 14(4): 443-449.

Jerry, K.L. Tan. 2008. Current Measures for the Evaluation of Acne Severity. Expert Rev. Dermatol., 3(5): 595-603.

Johansson, L., Linner, A., Sunden-Cullberg, J., Haggar, A., Herwald, H., Lore, K., et al. 2009. Neutrophil-derived hyper resistinemia in severe acute streptococcal infections. J. Immunol., 183: 4047-4054.

Konrad, A. et al. 2007. Resistin is an inflammatory marker of inflammatory bowel disease in humans. Eur. J. Gastroenterol. Hepatol., 19(12): 10704.

Kumar, S., Gupta, V., Srivastava, N., Gupta, V., Mishra, S., Mishra, S., Shankar, M.N., Roy, U., Chandra, A., Negi, M.P.S., and Kumar, S. 2014. Resistin $420 \mathrm{C} / \mathrm{G}$ gene polymorphism on circulating resistin, metabolicrisk 
factors and insulin resistance in adult women. Immunol. Lett., 162: 287-291.

Kunnari, A.M., Savolainen, E.R., Ukkola, O.H., Kesaniemi, Y.A., Jokela, M.A. 2009. The expression of human resistin in different leucocyte lineages is modulated by LPS and TNFalpha. Regul. Pept., 157: 57-63.

Kurokawa, I., William, D., Ju, Q., et al. 2009. New development in our understanding of acne pathogenesis \& treatment. Experimental dermatol., 18: 821-832.

Lehrke, M., Reilly, M.P., Millington, S.C., Iqbal, N., Rader, D.J., Lazar, M.A. 2004. An inflammatory cascade leading to hyperresistinemia in humans. PLoS Med., 1: e45.

Menzaghi, C., Coco, A., Salvemini, L., Thompson, R., De Cosmo, S., Doria, A., Trischitta, V. 2006. Heritability of serum resistin and its genetic correlation with insulin resistancerelated features in nondiabetic Caucasians. J. Clin. Endocrinol. Metab., 91: $2792-2795$.

Nagaev, I., Bokarewa, M., Tarkowski, A., Smith, U. 2006. Human resistin is a systemic immune-derived pro inflammatory cytokine targeting both leukocytes and adipocytes. PLoS One,
1: e31.

Osawa, H., Tabara, Y., Kawamoto, R., Ohashi, J., Ochi, M., Onuma, H., Nishida, W., Yamada, K., Nakura, J., Kohara, K., Miki, T., Makino, H., 2007. Plasma resistin, associated with single nucleotide polymorphism-420, is correlated with insulin resistance, lower HDL cholesterol, and highsensitivity C-reactive protein in the Japanese general population. Diabetes Care, 30: 1501 -1506.

Szabo, K. and Kemeny, L. 2011. Studying the genetic predisposing factors in the pathogenesis of acne vulgaris. Hum. Immunol., 72(9): 766-773.

Webster, G.F., Leyden, J.J., Musson, R.A. and Douglas, S.D. 2005. Susceptibility of Propionibacterium acnes to killing $\&$ degradation by human neutrophils $\&$ monocytes in vitro. Infect Immun., 49: 116-121.

Younis, S., Blumenberg, M. and Javed, Q. 2016. Resistin gene polymorphisms are associated with acne and serum lipid levels, providing a potential nexus between lipid metabolism and inflammation. Springer-Verlag Berlin Heidelberg. DOI 10.1007/s00403-0161626-y.

\section{How to cite this article:}

Hammadi A. Al-Hilali and Mohammed Jaafar AL-Anssari. 2016. Resistin (RETN) Gene rs 1862513 Polymorphisms and Acne vulgaris Patients. Int.J.Curr.Microbiol.App.Sci. 5(12): 415-422. doi: http://dx.doi.org/10.20546/ijcmas.2016.512.045 